\title{
El "Boomerang" de los Excedentes
}

\author{
MARCOS VERGARA ${ }^{(1)}$
}

En Diciembre de 1998, al cierre de la primera etapa de trabajo del Taller de Salud de la Fundación Chile 21 -institución donde se incubó el programa de gobierno del Presidente Lagos-, se había alcanzado la convicción de que sería necesario impulsar una reforma en el sector de la salud. Esto, se decía, era un "desafío ineludible" para el tercer gobiemo de la concertación. Así quedó plasmado en un documento especialmente editado por la Fundación, en cuya redacción reconozco haber colaborado!

En ese mismo documento, en la página 18 , al hacerse una pormenorizada revisión de lo obrado hasta la fecha en el sector de la salud por los gobiernos de la Concertación -un juicio a los aciertos y errores con un sesgo levemente autoflagelante, visto ahora en perspectiva- se decía lo siguiente:

...la discusión que se hizo en el Parlamento en torno a los excedentes de cotizaciones ratificó el sentido de propiedad individual de las personas sobre las cotizaciones para salud. Independientemente del tamaño de los recursos que se obtuvo ¿era eso lo que se buscaba?..."

En esta pregunta cabe detenerse, porque es evidente que la iniciativa legislativa a que se hace mención, contribuyó a ratificar la tesis de apropiación individual de las cotizaciones para la seguridad social en salud. Esto, que en verdad suena como una verdadera paradoja, ha sido así en la práctica desde la creación de las Instituciones de Salud Previsional. Nunca estuvo expresamente explicitado, pero ha estado implícito y seguramente también lo estuvo en el espíritu de quienes en esos entonces una junta de gobierno conformada por un represen- tante de cada una de las ramas de las fuerzas armadas- hubieron de legislar al respecto.

No obstante lo planteado en el párrafo anterior, frente a lo implícito hacía falta una ratificación. Y esta vino, como una suerte de "jurisprudencia", cuando los parlamentarios de gobiemo y muchos de la oposición que no querían devenir en impopulares - y que tampoco vieron mayores costos para la industria con la medida, sólo ventajas-, votaron a favor de la apropiación de los excedentes de las cotizaciones por parte de las personas. Esta medida, cuya recaudación neta es todavía discutible, trajo consigo costos enormes en el terreno de las bases fundamentales sobre las que construimos nuestra sociedad pues explicitó el carácter privado de las cotizaciones obligatorias para salud. Ahí están los verdaderos costos. Hoy, construido ese escenario, debatir acerca de la conformación de un Fondo Solidario o Compensatorio o como quiera que se le llame, que implique trasferencias de cotizaciones de ricos a pobres o de quienes tienen menores riesgos de enfermar a quienes tienen mayores riegos de enfermar ${ }^{2}$, se ha transformado en una cuestión en la que se han puesto en juego de nuevo dos modelos distintos de sociedad.

Desde mi punto de vista, lo que llevó a los parlamentarios a cometer ese severo error estratégico no sólo está explicado por la rentabilidad de corto plazo de la medida para cada uno de los legisladores -y también por alguna cuota de desconocimiento y de irresponsabilidad-, sino que lo está principalmente por la fuerte animadversión que en un sector importante de la Concertación de Partidos

(1) Escuela de Salud Pública. Universidad de Chile. mvergara@med.uchile.cl

Salud: Compromiso Ineludible para el Éxito del Próximo Gobiemo de la Concertación. Taller de Salud. Fundación Chile 21. Santiago de Chile. Noviembre de 1998.

2 Parámetros esenciales para el juicio de afairness» sobre los sistemas de salud que OMS hace en su publicación del 2000 y respecto de los cuales hay plena coincidencia entre los especialistas en la materia.

3 Se hace referencia al modelo de seguros individuales de corto plazo que selecciona por ingresos y tarifica por riesgos, y que bajo el formato Isapte forma parte del sistema de seguridad social de salud en Chile, así como al descreme de población beneficiaria producido sobre la base de esos mismos dos elementos. 
por la Democracia produce la presencia del aparato asegurador privado dentro de la seguridad social de la salud -con justa razón, a mi juicio, dado el formato y la evolución histórica del sistema por todos conocida $^{3}$-. Sin embargo, como hemos visto, no siempre es bueno dejarse llevar por las pasiones.

El documento de la Fundación Chile 21 admite claramente e intenta explicar de algún modo la ambivalencia de la Concertación y su autolimitación para producir durante los 90 las reformas de fondo en el sector de la salud, tanto público como privado. Dice así, al comenzar la página 19 :

"Sólo los temores de la transición pueden explicar el cuidadoso equilibrio de los últimos años por no tocar los intereses económicos de los dueños de las ISAPRE ni los intereses de los gremios".

Lo que está claro para nosotros al día de hoy es que la Concertación de Partidos por la Democracia no ha terminado de resolver sus indefiniciones en el terreno de la salud. No compartimos la idea de que aquéllas se deriven de la transición a la democracia, por lo menos ya no a estas alturas, cuando más de alguno la ha dado por concluida. Claramente hay cuestiones de fondo que no le han hecho la vida fácil al conglomerado al momento de optar: sí o no, con Isapre o sin Isapre, con privados o sin privados dentro de la seguridad social. Esto, que nos llevaría en cada caso por caminos muy distintos, no está resuelto.

Alternativas: si el camino elegido fuese sin participación de los privados en la seguridad social de la salud, entonces fuera las Isapre y fuera los hospitales y clínicas privadas y sumerjámonos sólo en un profundo e intenso proceso de modernización del monopolio público FONASA-SNSS, para garantizar a los ciudadanos calidad y oportunidad de servicios. $\mathrm{Si}$, como variante de lo anterior, la estrategia sólo fuese poner fuera a los privados del aseguramiento, por la razón que fuera, entonces fuera las Isapre pero que vengan los hospitales y clínicas privadas a prestar servicios a FONASA y a competir con los hospitales públicos por la calidad y oportunidad de los mismos. Si, por el contrario, la idea fuese que los privados participen dentro del sistema de seguridad social tanto en el aseguramiento como en la provisión, entonces cámbiese la natura- leza de las Isapre, créense Fondos Compensatorios, ábranse las camas de los hospitales públicos a todos los enfermos, pórtense los subsidios entre aseguradores y garantícese así a la ciudadanía calidad y oportunidad de servicios. Pero tómese una opción, una de verdad.

Comentamos antes en esta misma revista que considerando ya dada la existencia de un plan de salud garantizado de manera universal (AUGE), las restricciones al uso de las camas de los hospitales públicos así como las restricciones a la portabilidad de los subsidios eran inconsistentes con la idea del plan y creaban las condiciones para seguir manteniendo un sistema de salud dual, "irresoluto», que segmenta odiosamente a nuestros ciudadanos en categorías socio-sanitarias dentro de un mismo sistema de seguridad social, categorías que son crecientemente inaceptables en el mundo moderno. En efecto, estas medidas suficientes en sí mismas para mantener el "status quo", explican también porqué los parlamentarios de oposición asignan al Fondo Compensatorio un carácter "expropiatorio" y se oponen a su creación.

Vistas así las cosas $\measuredangle$ a qué responde, en definitiva, este modelo sectorial y su perpetuación? ¿Quiénes se benefician, finalmente, con la mantención de este "cuidadoso equilibrio"? He aquí preguntas que vamos a empezar a tener que responder, poco a poco, pues sus respuestas no son tan obvias. Tarea para la salud pública, para la sociología, la economía $y$ otras ciencias.

Mientras tanto, entonces, como un "boomerang", el producto de nuestras propias obras se vuelve contra nosotros y nos ofrece una nueva dificultad para avanzar hacia donde queremos. El Fondo Compensatorio que nos interesa instalar luce inconstitucional. Entonces nos hemos "pillado la cola", porque este fondo -que duda cabe- sí que resulta indispensable para la Reforma. Pero, de veras, ¿es que nos estamos haciendo tram. pas en el solitario? ¿Queremos hacer tortillas sin quebrar ningún huevo? ¿Hacia dónde es que queremos avanzar? ¿Constituye o no la integración social un objetivo de las políticas públicas? Si así fuese, ¿cómo le explicamos entonces a la gente los pasos que hemos venido dando? 